\title{
Design of a Long Endurance Titan VTOL Vehicle
}

\author{
Ravi Prakash, Robert D. Braun, Luke S. Colby, \\ Scott R. Francis, Mustafa E. Gündüz, \\ Kevin W. Flaherty, Jarret M. Lafleur \\ Guggenheim School of Aerospace Engineering \\ Georgia Institute of Technology \\ Atlanta, GA 30332 \\ 404-894-7783 \\ ravi_prakash@ae.gatech.edu \\ Henry S. Wright \\ NASA Langley Research Center \\ 100 NASA Drive \\ Hampton, VA 23681 \\ 757-864-6928 \\ Henry.S.Wright@nasa.gov
}

\begin{abstract}
Saturn's moon Titan promises insight into many key scientific questions, many of which can be investigated only by in situ exploration of the surface and atmosphere of the moon. This research presents a vertical takeoff and landing (VTOL) vehicle designed to conduct a scientific investigation of Titan's atmosphere, clouds, haze, surface, and any possible oceans. In this investigation, multiple options for vertical takeoff and horizontal mobility were considered. A helicopter was baselined because of its many advantages over other types of vehicles, namely access to hazardous terrain and the ability to perform low speed aerial surveys. Using a nuclear power source and the atmosphere of Titan, a turbo expander cycle produces the $1.9 \mathrm{~kW}$ required by the vehicle for flight and operations, allowing it to sustain a long range, long duration mission that could traverse the majority of Titan. Such a power source could increase the lifespan and quality of science for planetary aerial flight to an extent that the limiting factor for the mission life is not available power but the life of the mechanical parts. Therefore, the mission could potentially last for years. This design is the first to investigate the implications of this potentially revolutionary technology on a Titan aerial vehicle.
\end{abstract}

\section{TABLE OF CONTENTS}

1. INTRODUCTION.................................................1

2. MISSION ASSUMPTIONS AND REQUIREMENTS .....2

3. CONCEPT SELECTION ..........................................2

4. POWER SYSTEM...................................................3

5. VEHICLE SIZING ....................................................4

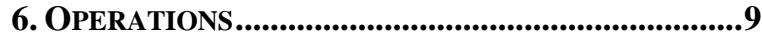

6. Planetary Protection........................................9

7. BENEFIT OF CUSTOM RTG ...................................10

8. CONCLUSIONS .....................................................10 10

APPENDIX ...............................................................10

REFERENCES ......................................................14

1

${ }^{1}$ 0-7803-9546-8/06/\$20.00@ 2006 IEEE
BIOGRAPHY ......... ERROR! BOOKMARK NOT DEFINED.

\section{INTRODUCTION}

Titan, the largest moon of Saturn and the only moon in our solar system with a dense atmosphere, may provide clues to how life began on Earth sometime after the Earth was formed 4.6 billion years ago. The Earth and Titan share a bond in that they are the only planetary bodies in the solar system with a substantial amount of nitrogen (78\% and 95\%, respectively). Titan's atmosphere also contains about $3 \%$ methane, which along with nitrogen triggers chemical reactions to produce hydrocarbons that lead to more complex organic compounds that are the building blocks for life $[1,2]$. Evidence of pre-biotic activity on Earth has been erased by the evolution of the Earth's atmosphere and plate tectonics [1].

Data from the Cassini-Huygens mission has returned and continues to return valuable data that reveal information regarding Titan's atmosphere and surface, paving the way for a more thorough exploration of the planet by an autonomous aircraft. The next step in exploring the planet would be to go beneath the thick atmospheric haze and obtain high resolution imagery and composition of the atmosphere, surface, and any possible oceans. From this information, the relevance of any pre-biological chemistry to the origin of life on Earth can be determined [1].

To adequately explore Titan's atmosphere, surface, and any possible oceans, the mission requires an aerial vehicle capable of flying a nominal mission for a duration of $3-4$ months. Titan is ideal for flight in that the surface gravity is about 1/7 that of Earth with a density of about 4 times Earth. Two options are being considered for the aerial vehicle by a NASA Vision Mission Study: an airship and a 
Vertical Takeoff and Landing (VTOL) vehicle. NASA Langley Research Center (LaRC) designed the airship concept, while the Space Systems Design Laboratory at the Georgia Institute of Technology designed the VTOL platform for this mission [1]. This paper will focus on the design of the VTOL vehicle, including its entry into the Titan atmosphere.

\section{Mission AsSUMPTIONS AND REQUIREMENTS}

The mission assumed a launch on a Delta IV-Heavy in April 2018, allowing new and emerging technologies to be developed and used for this mission. To determine which technologies could be used, a Technology Readiness Level (TRL) of level 6 was required by the year 2014.

An orbiter was designed by LaRC, and was assumed to be operational for 40 months after Titan orbit insertion. The orbiter has a data rate of 1.1 Gbits, and is available for downlink to Earth during about $45 \%$ of its orbit.

The allocated mass for the vehicle and all components inside the aeroshell was $400 \mathrm{~kg}$. A 30\% mass margin was used in sizing the vehicle, along with various component level contingencies. The vehicle had to carry a science payload of $32.4 \mathrm{~kg}$.

A baseline mission was defined for the vehicle in which it was to climb vertically to $1 \mathrm{~km}$ and hover for 1 minute to acquaint itself with the surroundings as well as find interesting areas to explore. Then, the vehicle was to climb to an altitude of $10 \mathrm{~km}$ and traverse a $50 \mathrm{~km}$ range while having the ability to take scientific measurements. After a brief period of time, the vehicle was to descend until it found a relatively flat landing area. The baseline mission had to be repeated several times for a thorough investigation of Titan. In the event that a body of liquid methane exists on Titan, the vehicle was designed to float in liquid methane.

\section{CONCEPT SELECTION}

The VTOL selection started with a set of initial concepts which included an entomopter, ornithopter, hopper, and rotorcraft. An entomopter is an insect-like robot that has rapidly flapping wings. After preliminary sizing, it was determined that this concept was infeasible for this mission because it requires a low Reynolds number to operate [3], and the high density of Titan would require that the wingspan of the entomopter be on the order of $5 \mathrm{~mm}$. Thus, the entomopter would not be able to carry the required payload.

An ornithopter is a larger, bird-like robot that also has flapping wings. This option was deemed infeasible because of its technological immaturity. Currently, the ornithopter is at a TRL 3, and it is uncertain whether the concept could be at an appropriate TRL to be used for this mission. In addition, ornithopters are very fragile, and Titan's unknown terrain may be too hazardous for the ornithopter to make multiple landings.

A hopper is a device that uses either a mechanical spring or chemical propellant to "leap" through the atmosphere. This concept has the benefit that it takes advantage of Titan's low gravity. However, while in flight, the mechanical hopper does not have much maneuverability and therefore does not have precision landing capabilities. The chemical hopper would require a lot of propellant to sustain a long duration mission. Also, with either hopper design, the mission would essentially be over if it landed in liquid methane. Therefore, the hopper was considered unsatisfactory.

The rotorcraft concept was baselined because of its many advantages over the other concepts. Unlike the previous concepts, the rotorcraft has a high payload capacity, high TRL, and precision landing capabilities. In addition, rotorcrafts have great maneuverability and can be used as scouts to aid in future human exploration of other planets. The limiting case for the rotorcraft is its high power requirement. However, Titan is ideally suited for a rotorcraft because of its thick atmosphere. A power study on planetary aerial vehicles by Lafleur showed that a rotorcraft on Titan requires about 30 times less power than on Earth, and about 60 times less power than on Mars [4].

Six different rotorcraft configurations were analyzed to determine an optimal configuration that could satisfy all the mission requirements: double blade, quad blade, coaxial, intermeshing, tandem, and tilt rotor (Figure 1).

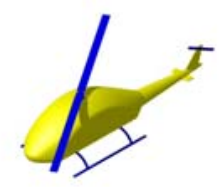

(a)

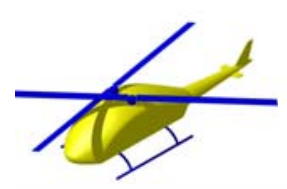

(d)

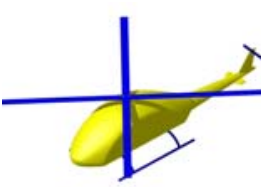

(b)

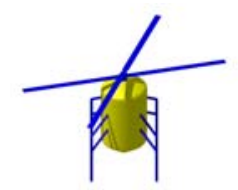

(c)

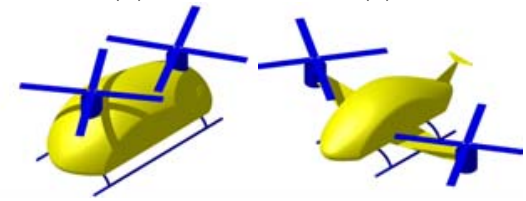

(e)

Figure 1 - Analyzed Rotorcraft Configurations

Each rotorcraft configuration has its own advantages and disadvantages. Both the double and quad blade helicopters (Figures $1 \mathrm{a}$ and $1 \mathrm{~b}$ ) are well proven designs, with the double blade helicopter having less blade drag than any of the other configurations. However, these designs require a tail rotor for stability purposes which increases the power 
requirement. The tail on these helicopters also has packaging implications inside the aeroshell. The coaxial and intermeshing helicopters (Figures 1c and 1d) have two counter-rotating blades which eliminate the need to produce a torque for stability; thus these helicopters do not require a tail rotor allowing all the generated power to go towards producing lift. However, rotor interference effects between the two rotors increase the drag and consequently power required for these two designs. Also, the blades must be more rigid to prevent them from coming into contact with each other, increasing the blade mass. The tandem helicopter (Figure 1e) has a wide center of gravity range, increasing its stability over other helicopter designs. The tandem helicopter also has a greater payload capacity than the other designs. However, because of its increased size, the tandem helicopter has a larger power requirement and greater aeroshell packaging difficulties. The tilt rotor (Figure 1f) design can have a wide lateral center of gravity variation in addition to its increased efficiency during forward flight. However, this design is inefficient during hover and has stability problems when transitioning to and from forward flight.

\section{Power System}

It was quickly realized that obtaining the required power within the available mass would be the largest driving factor in the design of the vehicle. Figure 2 below shows that the power required for flight increases somewhat quadratically with increasing mass. Therefore, for a helicopter mass of about $400 \mathrm{~kg}$ requires about $1.8 \mathrm{~kW}$ of power (before margin).

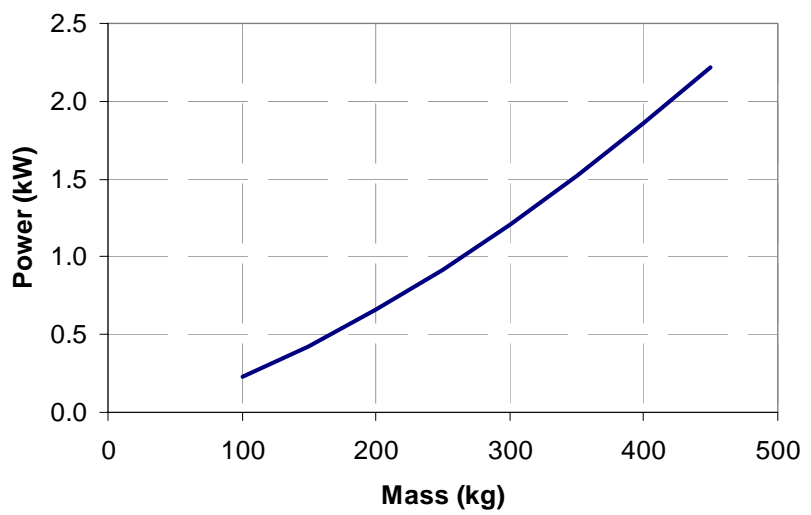

Figure 2 - Power Required for Flight

Since Titan is about 9.5 AU from the Sun, the only viable options for large power requirements are: chemical, batteries trickle charged via an RTG, or some form of gas turbine system that takes advantage of Titan's atmosphere. The chemical option was discarded for its short mission life. The latter two power options were sized, and it was determined that batteries trickled charged with an RTG would not satisfy the mass requirement. Therefore, it was decided that a gas turbine system, known as the turbo expander cycle, was the best possible option for power generation.

The turbo expander cycle is basically a simplified version of a Brayton cycle familiar from gas turbines such as a turbojet or turbofan. In this case, the combustor is merely replaced by a heat exchanger enclosing a NASA developed MultiMission Radioisotope Thermal Generator (MMRTG) to capture the waste heat from radioactive decay of Plutonium 238 in the MMRTG core. This waste heat is normally radiated away via large cooling fins on the exterior of the MMRTG, but for this application, the MMRTG will be slightly modified in that the radiator fins will be replaced by a heat exchanger. However, to reduce qualification and development costs, the interior thermoelectric components of the RTG will not be modified. As a result, the surface temperature of the casing will be a moderately hot $200^{\circ} \mathrm{C}$ as opposed to the plutonium core temperature of $1000^{\circ} \mathrm{C}$. However, given that Titan's atmosphere is nitrogen gas at approximately $-180^{\circ} \mathrm{C}$, there is an ample temperature gradient for power extraction [6].

The gas turbine type for this concept is a centrifugal turbine and compressor, similar to a turbocharger. A centrifugal configuration is ideally suited to this concept because the low power levels of under $5 \mathrm{~kW}$ and correspondingly low mass flow rates are simply too small for an axial flow gas turbine, which requires larger rotor radii before the axial blades become efficient. Also, the centrifugal configuration is easily connected to a large heat exchanger that does not have to be mounted axially between the compressor and turbine as in an axial gas turbine. Finally, as this system is being used to generate electrical power, it is quite convenient to simply fill the space between the compressor and turbine with a bearing section that doubles as a brushless alternator for extracting electrical power. In this way, no gear linkages are required to convert the shaft work into electrical power since the bearings that support the compressor and turbine also hold the alternator rotor, and the brushless stator is simply part of the bearing casing. A notional drawing of this concept is shown in Figure 3 below, and a schematic of this concept is shown in Figure 4 [6]. 


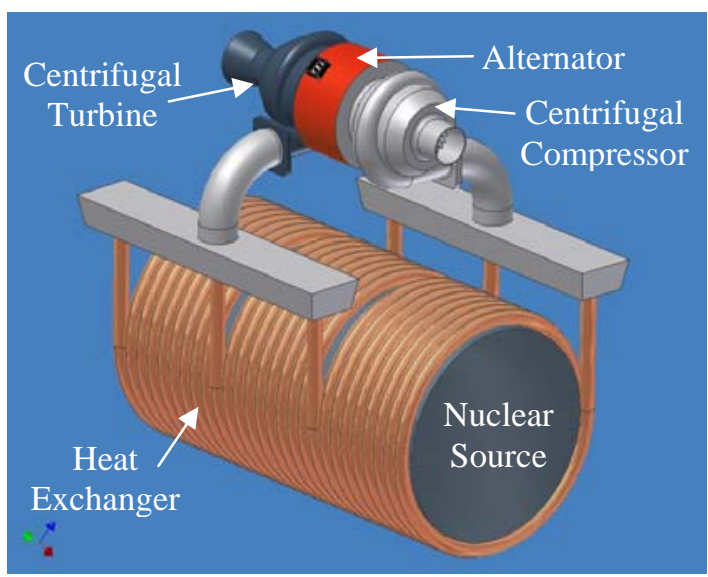

Figure 3 - Notional Drawing for Turbo Expander

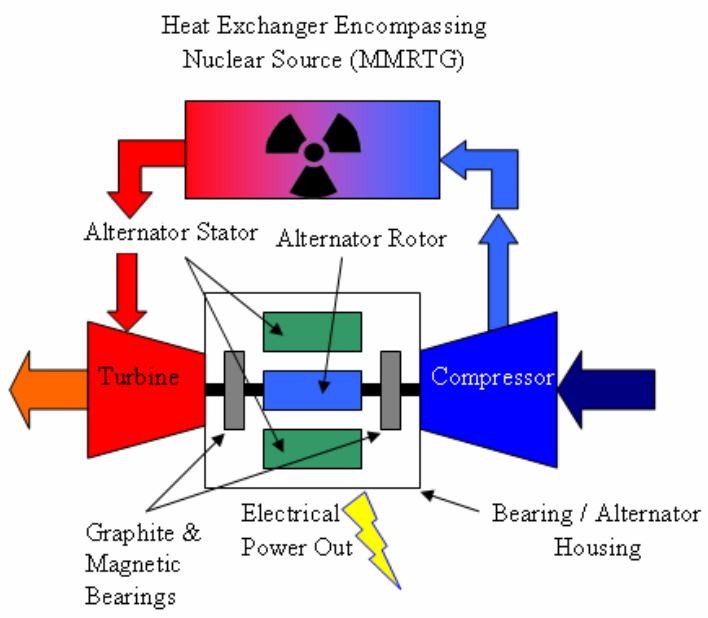

Figure 4 - Schematic of Turbo Expander Cycle

In analyzing this system's theoretical performance, two approaches were taken. First, a simple modified ideal Brayton cycle analysis was performed. This analysis suggested that given a power input of $2100 \mathrm{~W}$, the theoretical power available would be approximately $960 \mathrm{~W}$. Then a more detailed analysis involving computing the flow properties throughout each system component was performed for a specific set of off-the-shelf system components to be used in a physical proof of concept. This more detailed analysis suggested a total power output of $580 \mathrm{~W}$ for a single MMRTG waste heat power input. This represents a 5 fold increase over the power available from the thermoelectric effect alone and clearly demonstrates the utility of such a device. A simplified model of the system was created to allow design optimization routines to iterate the vehicle concept without a detailed component solution of the turbo expander having to be run for each design iteration. Information on the proof of concept as well as more information on the turbo expander cycle is available in reference [6].

In accordance with the Announcement of Opportunity for this NASA Vision Mission Study, the vehicle must use prespecified RTG capability limits in lieu of other more advanced capabilities. Therefore, a custom RTG cannot be considered for this mission, although the advantages of using one are considered in Section 7 of this report.

\section{VEHICLE SIZING}

\section{Approach}

Multi-disciplinary optimization (MDO) was used to analyze each helicopter concept. The helicopter analysis consisted of an investigation in each of the following subsystems: aerodynamics, propulsion, communications, command and data handling, attitude determination and control, thermal, power, and structures. Models for each subsystem were integrated into a system design tool called ModelCenter to optimize the configuration for a minimum gross weight using rotor radius, blade chord length, and maximum allowable cruise velocity as design variables. Using ModelCenter allowed outputs from one subsystem to be linked as inputs to another subsystem, allowing numerous designs to be evaluated for rapid optimization (Figure 5). The optimization was run to size each helicopter for missions of varying difficulty, including the baseline mission.

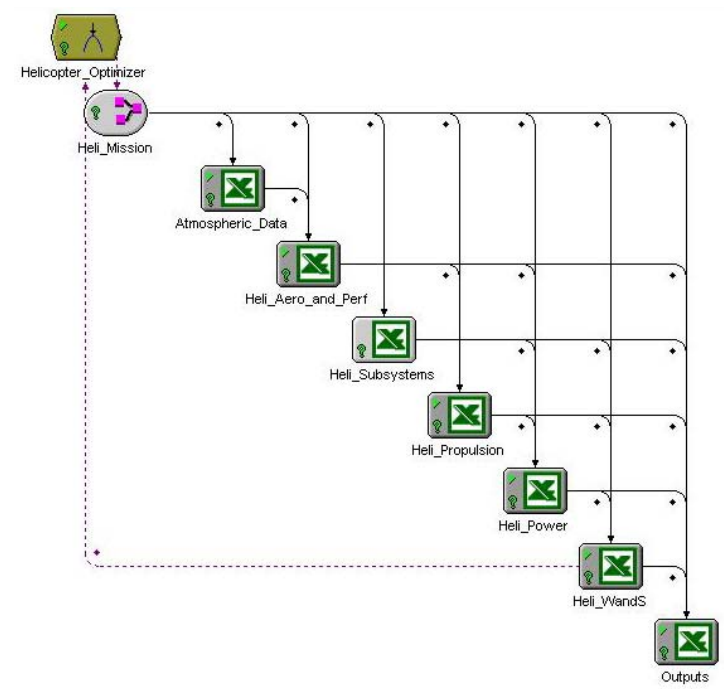

Figure 5 - Design Structure Matrix of Vehicle Subsystems

\section{Aerodynamics}

Using basic helicopter aerodynamics that were modified for the environment on Titan, the power required for flight was determined as a function of velocity, and is shown in Figure 6. This power includes losses due to drag from the helicopter configuration as well as the inflatable flotation device and antennas. 


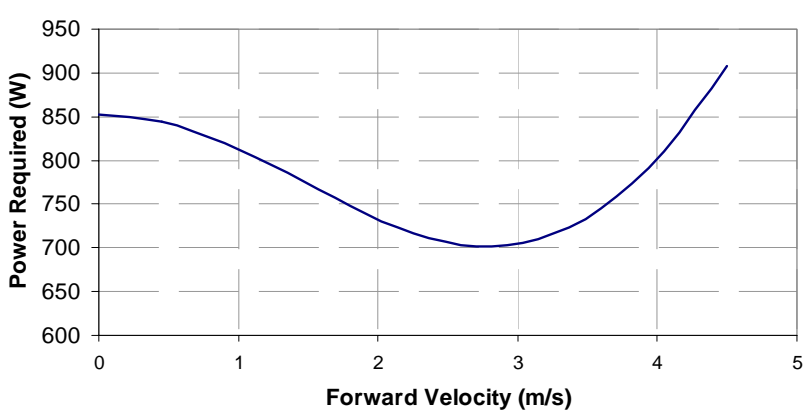

Figure 6 - Power Required vs. Forward Velocity

Figure 6 shows that initially, as the helicopter gains forward velocity, the power required for flight decreases, but eventually, the high drag forces dominate and cause the power required for flight to increase again. It is not until the helicopter reaches a velocity of about $4.3 \mathrm{~m} / \mathrm{s}$ that the power required for flight reaches the power required for hover. Therefore, the helicopter can be sized to meet the power required to hover, which in this case is $852.8 \mathrm{~W}$. With the addition of a 30\% contingency, 20\% power margin, and a conservative rotor efficiency factor of $85 \%$, the power required for flight comes out to $1560.9 \mathrm{~W}$.

Figure 6 also shows that the most efficient forward flight speed is $2.8 \mathrm{~m} / \mathrm{s}$. At this speed, the rotor requires the least power, about $695.2 \mathrm{~W}$. If the helicopter travels at this speed, it can use the remaining power to make maneuvers such as climbing and banking. At this forward velocity, the resulting maximum rate of climb is $0.6 \mathrm{~m} / \mathrm{s}$.

\section{Propulsion Subsystem}

The propulsion subsystem sized the helicopter rotor so that the helicopter could produce the necessary lift. The resulting blade radius is $1.6 \mathrm{~m}$. The weight breakdown structure (WBS) for the propulsion system is shown below in Table 1.

Table 1. Propulsion Subsystem WBS

\begin{tabular}{|l|c|}
\hline \multicolumn{1}{|c|}{ Component } & $\begin{array}{c}\text { Maximum Expected Mass } \\
\text { with 30\% Margin (kg) }\end{array}$ \\
\hline Main Rotor & 7.4 \\
\hline Blade & 6.7 \\
\hline Axel & 0.7 \\
\hline Motor & 5.6 \\
\hline Total & $\mathbf{1 3 . 0}$ \\
\hline
\end{tabular}

\section{Communication Subsystem}

The communications subsystem is outlined in Table 2 below. With these components, the helicopter will be able to communicate with the orbiter whenever the orbiter is overhead. A low gain antenna will be placed on top of the helicopter rotor as well as on the end of the helicopter tail sticking up vertically so that it will not interfere with the rotor and only produce a small amount of drag (Figure 7).
Table 2. Communication Subsystem WBS

\begin{tabular}{|l|c|c|}
\hline \multicolumn{1}{|c|}{ Component } & $\begin{array}{c}\text { Max Expected } \\
\text { Mass with 30\% } \\
\text { Margin (kg) }\end{array}$ & $\begin{array}{c}\text { Max Expected } \\
\text { Power with 20\% } \\
\text { Margin (W) }\end{array}$ \\
\hline $\begin{array}{l}\text { X-Band Omni - } \\
\text { LGA (2) }\end{array}$ & 0.2 & 0 \\
\hline $\begin{array}{l}\text { SDST X-up/X- } \\
\text { down }\end{array}$ & 4.6 & 0 \\
\hline X-Band TWTA & 3.0 & 0 \\
\hline UHF Transceiver & 7.6 & 93.6 \\
\hline UHF Transceiver & 7.6 & 0 \\
\hline UHF Omni & 2.5 & 0 \\
\hline UHF Diplexer (2) & 1.6 & 0 \\
\hline $\begin{array}{l}\text { Additional } \\
\text { Hardware }\end{array}$ & 10.2 & 0 \\
\hline Total & $\mathbf{3 7 . 3}$ & $\mathbf{9 3 . 6}$ \\
\hline
\end{tabular}

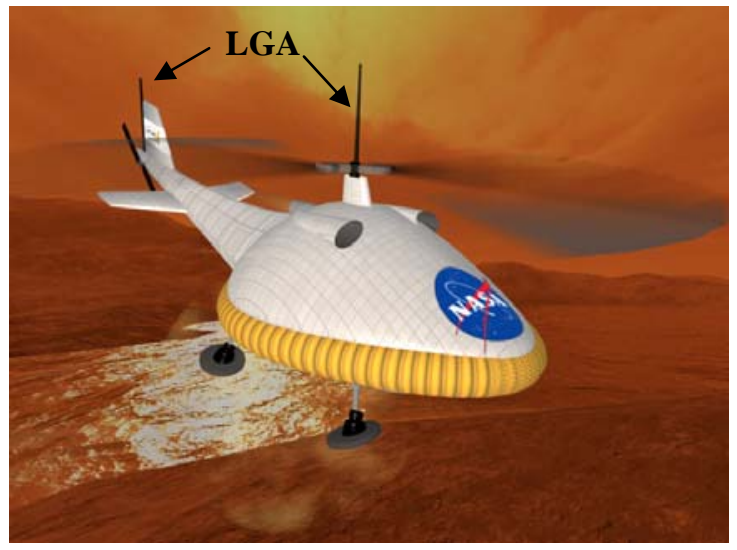

Figure 7 - Low Gain Antennas on Helicopter

\section{Command and Data Handling Subsystem}

The breakdown for the command and data handling (C\&DH) subsystem for the helicopter is shown in Table 3 below. The first eight items shown are considered a total integrated avionics unit. Two of these units will be on the helicopter for redundancy. The mass shown is the total mass with contingency for both integrated avionics units. However, since only one unit will be operating at any given time, the power shown is for a single unit with contingency included.

Table 3. C\&DH Subsystem WBS

\begin{tabular}{|l|c|c|}
\hline \multicolumn{1}{|c|}{ Component } & $\begin{array}{c}\text { Max Expected } \\
\text { Mass with 30\% } \\
\text { Margin (kg) }\end{array}$ & $\begin{array}{c}\text { Max Expected } \\
\text { Power with 20\% } \\
\text { Margin (W) }\end{array}$ \\
\hline $\begin{array}{l}\text { Flight Processor; } \\
\text { >200 MIPS, } \\
\text { RAD750, cPCI }\end{array}$ & 0.9 & 14.5 \\
\hline $\begin{array}{l}\text { Digital I/O - } \\
\text { CAPI Board }\end{array}$ & 0.9 & 4.3 \\
\hline State of Health & 0.9 & 4.3 \\
\hline
\end{tabular}




\begin{tabular}{|l|c|c|}
\hline $\begin{array}{l}\text { and Attitude } \\
\text { Control - SMACI }\end{array}$ & 1.9 & 8.6 \\
\hline $\begin{array}{l}\text { Power } \\
\text { Distribution - } \\
\text { PDB (2) }\end{array}$ & 0.9 & 4.3 \\
\hline $\begin{array}{l}\text { Power Control - } \\
\text { PCATI }\end{array}$ & 1.3 & 0 \\
\hline Mother Board & 1.3 & 17.3 \\
\hline $\begin{array}{l}\text { Power Converters } \\
\text { (For Integrated } \\
\text { Avionics Unit) }\end{array}$ & 5.3 & 0 \\
\hline Chassis & 2.7 & 0.8 \\
\hline $\begin{array}{l}\text { Solid State Data } \\
\text { Recorder }\end{array}$ & $\mathbf{1 6 . 1}$ & $\mathbf{5 4 . 1}$ \\
\hline Total & & \\
\hline
\end{tabular}

\section{Attitude Determination and Control Subsystem}

The attitude determination and control subsystem (ADCS) is outlined in Table 4 below. The items listed in Table 4 allow the helicopter to orient itself as desired. The mass and power shown in this table includes the appropriate contingencies for each item.

Table 4. ADCS Subsystem WBS

\begin{tabular}{|l|c|c|}
\hline \multicolumn{1}{|c|}{ Component } & $\begin{array}{c}\text { Max Expected } \\
\text { Mass with 30\% } \\
\text { Margin (kg) }\end{array}$ & $\begin{array}{c}\text { Max Expected } \\
\text { Power with 20\% } \\
\text { Margin (W) }\end{array}$ \\
\hline Sun Sensors (2) & 1.2 & 0.7 \\
\hline IMU & 6.2 & 29.0 \\
\hline IMU-Spare & 6.2 & 0 \\
\hline Radar Altimeter & 8.0 & 47.0 \\
\hline $\begin{array}{l}\text { Antennas for Radar } \\
\text { Altimeter (2) }\end{array}$ & 0.5 & 0 \\
\hline $\begin{array}{l}\text { Absorber for Radar } \\
\text { Altimeter }\end{array}$ & 0.6 & 0 \\
\hline $\begin{array}{l}\text { Air Data System } \\
\text { with pressure and } \\
\text { temperature (2) }\end{array}$ & 8.4 & 9.4 \\
\hline Total & $\mathbf{3 1 . 1}$ & $\mathbf{8 6 . 1}$ \\
\hline
\end{tabular}

\section{Thermal Subsystem}

The thermal subsystem for the helicopter ensures that the electronics, sensors, batteries, and other components remain within their allowable temperatures. The thermal subsystem consists of multi-layer insulation, loop heat pipes to reroute some of the MMRTG heat, temperature sensors, and radioactive heater units. The mass of the thermal subsystem was estimated as $4 \%$ of the spacecraft dry mass, and the power required was estimated as $5 \%$ of the total subsystem power requirement (total power minus power required for flight). The result was a mass of $14.0 \mathrm{~kg}$ and power requirement of $26.9 \mathrm{~W}$ for the thermal subsystem.

\section{Power Subsystem}

The turbo expander cycle will provide the helicopter with the necessary power for each of the subsystems, as well as enable the helicopter to accomplish its long endurance mission. The turbo expander was sized based on the number of MMRTGs required to provide this total helicopter operating power. In this turbo expander cycle, the incoming cold, dense, Titan air is passed through a heat exchanger wrapped around three MMRTGs. The heated air is then exhausted through a turbine which is connected to a shaft for extracting power. The shaft is connected to an alternator for extracting electrical power to turn the rotor, allowing the rotor's rate of spin to be controlled. The assumed efficiencies of the engine are shown below in Table 5, leading to a system efficiency of about $38 \%$.

Table 5. Engine Component Efficiencies

\begin{tabular}{|l|c|}
\hline \multicolumn{1}{|c|}{ Component } & Efficiency (\%) \\
\hline Compressor & 76 \\
\hline Heat Exchanger & 88 \\
\hline Turbine & 68 \\
\hline Alternator & 93 \\
\hline Electric Motor & 90 \\
\hline Total & $\mathbf{3 8 . 1}$ \\
\hline
\end{tabular}

The power breakdown for the major subsystems is summarized in Table 6. Based on this total operating power, the power system requires three RTGs. As the power margin increases above $20 \%$, the total operating power increases enough so that an additional MMRTG is needed. The additional weight from the extra MMRTG increases the power required for flight, which in turn will require even another MMRTG. This cycle continues and the solution does not converge. Therefore, if a higher power margin is desired, a custom MMRTG would have to be built. This idea is discussed in further detail in Section 7 .

Table 6. Helicopter Power Breakdown by Subsystem

\begin{tabular}{|l|c|c|}
\hline \multicolumn{1}{|c|}{ Subsystem } & $\begin{array}{c}\text { Maximum } \\
\text { Expected } \\
\text { Power (W) }\end{array}$ & $\begin{array}{c}\text { Maximum Expected } \\
\text { Power with 20\% } \\
\text { Margin (W) }\end{array}$ \\
\hline Propulsion & 1300.7 & 1560.9 \\
\hline Communication & 78.0 & 93.6 \\
\hline C\&DH & 45.1 & 54.1 \\
\hline ADCS & 71.8 & 86.1 \\
\hline Thermal & 22.4 & 26.9 \\
\hline Payload & 90.2 & 108.2 \\
\hline Total & $\mathbf{1 6 0 8 . 2}$ & $\mathbf{1 9 2 9 . 8}$ \\
\hline
\end{tabular}

Because the turbo expander relies on the compressor to bring air into the engine, batteries will be used for the initial engine startup on Titan. From then on, the engine will not shut down until a mechanical failure occurs. While this form of operation will wear the mechanical parts faster than turning the engine on and off, the risk of repeatedly starting the engine is eliminated. With the engine running, there is 
no need for a thermal system to remove the MMRTG heat, leading to a mass savings on the thermal subsystem. With a $20 \%$ power margin and three MMRTGs, the power system has the mass breakdown shown in Table 7 .

Table 7. Power Subsystem Mass Breakdown

\begin{tabular}{|l|c|}
\hline \multicolumn{1}{|c|}{ Component } & $\begin{array}{c}\text { Maximum Expected Mass } \\
\text { with 30\% Margin (kg) }\end{array}$ \\
\hline $2^{\text {nd }}$ Generation MMRTG (3) & 86.2 \\
\hline Battery (for initial startup) & 0.5 \\
\hline Turbomachinery & 6.7 \\
\hline Turbine & 1.5 \\
\hline Compressor & 1.5 \\
\hline \multicolumn{1}{|c|}{ Piping } & 3.6 \\
\hline Electric Motor & 1.8 \\
\hline Alternator & 1.8 \\
\hline Total & $\mathbf{9 7 . 0}$ \\
\hline
\end{tabular}

\section{Structure Subsystem}

The structure subsystem was sized based on the volume needed to accommodate all of the other subsystems. The summation of the volumes for the subsystems equaled 0.53 $\mathrm{m}^{3}$. A $50 \%$ margin was added to the volume to account for the fact that there will be spacing between components as well as additional fittings, etc. Thus, the helicopter was sized for a volume of $0.80 \mathrm{~m}^{3}$. Assuming an ellipsoid for a body, the helicopter body is a $2.56 \times 0.77 \times 0.77 \mathrm{~m}$ ellipsoid with a $0.75 \mathrm{~m}$ tail. The tail includes a $0.3 \mathrm{~m}$ rotor radius to counteract the torque caused by the main rotor. The vehicle center of mass must be directly below the main rotor for the helicopter to perform properly. Therefore, the subsystems need to be placed accordingly.

To keep the mass of the structural frame low, the design was kept as simple as possible. The entire structural frame is made of graphite-epoxy composites and consists of one "ring" around the centerline of the fuselage, two tilted vertical ellipses, two top and two bottom connections between ellipses, and one tail beam. Four telescopic legs serve as the landing gear, and they are attached to the tilted vertical ellipses. In the event that the helicopter encounters a rough landing, the loads on the landing gear will be transferred to the stronger members of the structure. Furthermore, if the helicopter lands on an uneven surface, the telescopic legs will automatically adjust to level the helicopter. The main components of the structure are shown in Figure 8 below. Other structural members may be added to the bottom of the fuselage for mounting the various subsystems.

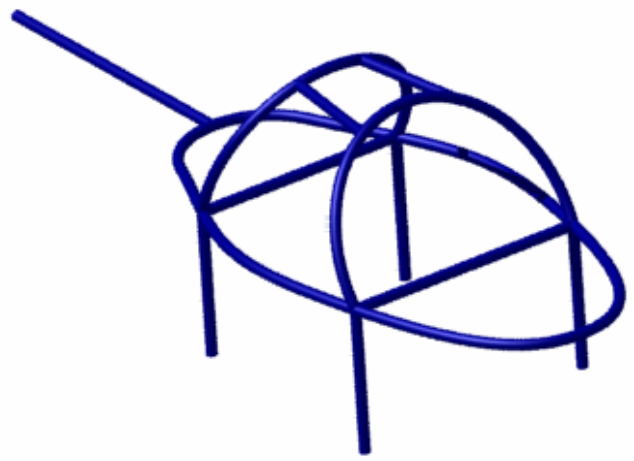

Figure 8 - Helicopter Structural Frame

In lieu of performing a launch and entry loads analysis, the helicopter structural mass was doubled, and it was assumed that this sturdier structure could withstand the conditions at both launch and entry, including the structural vibrations that arise during launch for the Delta IV-Heavy. The resulting maximum expected structural mass with a $30 \%$ margin is $69.9 \mathrm{~kg}$.

\section{Flotation Device}

Additionally, the helicopter must be able to float in the event that it lands in liquid methane. Therefore, an inflatable flotation device composed of the durable material Vectran (same material as the airbags for the Mars Exploration Rovers) will be around the body of the helicopter (Figure 9). The flotation device is inflated with helium using helium cartridges to a pressure of about $50 \mathrm{psi}$ as soon as the helicopter leaves the aeroshell. The flotation device protrudes $0.24 \mathrm{~m}$ on all sides of the helicopter and has a material thickness of $0.25 \mathrm{~mm}$, leading to a mass of $2.2 \mathrm{~kg}$ for the material and $2.2 \mathrm{~kg}$ for the helium gas cartridges.

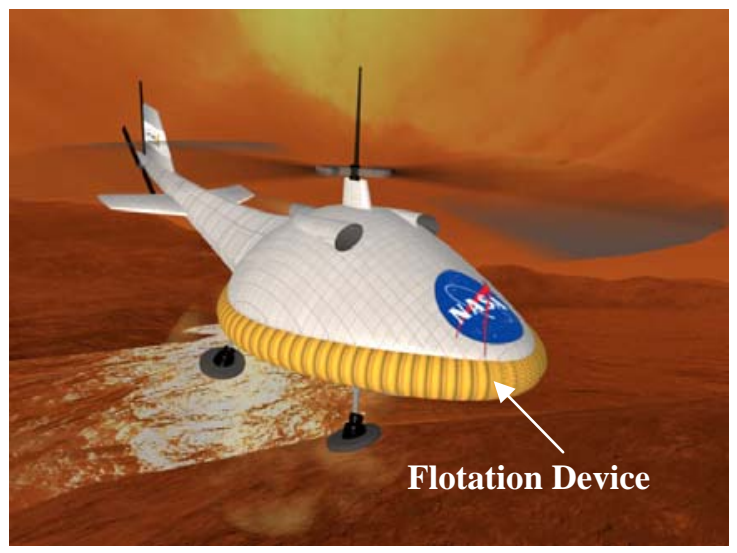

Figure 9 - Flotation Device on Helicopter

\section{Subsystem Summary}

A summary of the subsystem masses for the helicopter is given in Table 8 and Figure 10. Figure 10 shows that the power system which utilizes three MMRTGs is the biggest contributor to the mass, while the actual vehicle structure is the second leading contributor. 
Table 8. Helicopter Subsystem Mass WBS

\begin{tabular}{|l|c|}
\hline \multicolumn{1}{|c|}{ Subsystem } & $\begin{array}{c}\text { Maximum Expected Mass } \\
\text { with 30\% Margin (kg) }\end{array}$ \\
\hline Propulsion & 13.0 \\
\hline Communications & 37.3 \\
\hline C\&DH & 16.1 \\
\hline ADCS & 31.1 \\
\hline Thermal & 14.0 \\
\hline Payload & 36.0 \\
\hline Power & 97.0 \\
\hline Structure & 69.9 \\
\hline Flotation Device & 4.4 \\
\hline Total & $\mathbf{3 1 8 . 8}$ \\
\hline
\end{tabular}

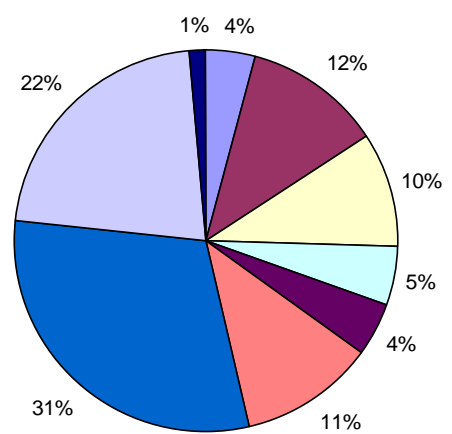

\begin{tabular}{|l|}
\hline$\square$ Propulsion \\
$\square$ Communication \\
$\square$ ADCS \\
$\square$ C\&DH \\
$\square$ Thermal \\
$\square$ Payload \\
$\square$ Power (Gas Expander) \\
$\square$ Structure \\
Inflatable Tube \\
\hline
\end{tabular}

Figure 10 - Helicopter Subsystem Mass WBS

With the dimensions given earlier, the helicopter fits inside the aeroshell without the need to fold any parts, which allows the structure to withstand greater loads and increases the probability of mission success. The helicopter is attached to the aeroshell in several locations, including supports connecting each leg of the landing gear as well as the main body and tail to the heatshield. Also, there are supports connecting the body of the helicopter to the side of the aeroshell to withstand lateral loads. The rotor is held to the aeroshell by several supports, and the blades are attached to the helicopter to dampen the vibrations to the blades. These supports are shown in Figure 11 below. The total mass of the supports is $39.0 \mathrm{~kg}$.

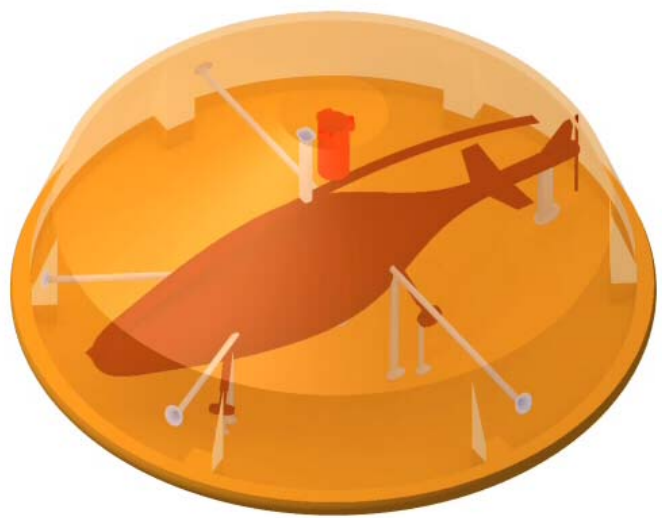

Figure 11 - Helicopter Inside Aeroshell

\section{Entry, Descent, Transition to Flight}

The entry, descent, and transition to flight (EDT) analysis for the helicopter was performed using a NASA developed tool called Program to Optimize Simulated Trajectories (POST). Two entry, descent, and transition to flight options were explored. One was a landing system in which the helicopter and a lander would land on the surface before taking off. The other was a mid-atmospheric deployment of the helicopter from the aeroshell where the helicopter would fly before landing.

For the landing option, a lander was sized based on a landing system for the Mars Exploration Rovers (MER) so that the lander would be able to properly orient the helicopter. The landing system for this application was modified so that no airbag would be used, and the lander would have 6 petals (base, top, 4 sides) instead of the 4 petals used on MER. Having more petals allows the helicopter to fit more easily inside the lander and effectively reduces the lander mass and volume. Since the gravity on Titan is less than the gravity on Mars, it is easier for a lander on Titan to orient the vehicle upright; therefore, smaller motors are required. Also, the impact velocity for the lander on Titan is much less than the impact velocity of the MER lander on Mars, allowing the structure to be lighter. The result was a landing system that weighed 161.0 $\mathrm{kg}$.

Also for the landing option, an inflatable flotation device was sized to fit around the lander so that the lander could float if it landed in liquid methane. The mass of the inflatable flotation device came out to $5.3 \mathrm{~kg}$. With the 39.0 $\mathrm{kg}$ structural supports from the helicopter to the aeroshell, the helicopter can have a mass of only $194.7 \mathrm{~kg}$ to satisfy the $400 \mathrm{~kg}$ mass limit. However, the helicopter using the turbo expander cannot be designed with this mass. Therefore, a land first option was determined to be infeasible given the mass constraint.

The mid-atmospheric deployment option led to an acceptable solution. In this scenario, the parachute also deploys at Mach 1.1. Then, at an altitude below $36 \mathrm{~km}$, when the heat rate from the descent is less than $10^{-5} \mathrm{~W} / \mathrm{cm}^{2}$, pyros will disconnect the helicopter from the heatshield and backshell. The heatshield will be jettisoned as it is no longer needed, allowing the entry to be slowed even further. The backshell, however, will ascend up the parachute riser because the atmosphere underneath is exerting an upward force on it that is greater than the force on the parachute. Therefore, the backshell falls slower than the parachute and rises relative to the parachute risers. At this point, the helicopter is still attached to the parachute and is exposed to the Titan environment. The helicopter needs to be exposed to the environment because the power system operates using Titan's atmosphere. Batteries on the helicopter will provide the initial power to startup the helicopter's engine. After one minute, the turbo expander will be fully functioning and 
both the backshell and parachute will be released. When the helicopter is a safe distance away from the parachute and backshell, the turbo expander will attach itself to the rotor shaft and start spinning the blades to a high enough rpm so that the helicopter can produce sufficient lift to commence its initial flight into the Titan atmosphere. The EDT summary for this option is shown in Figure 12.

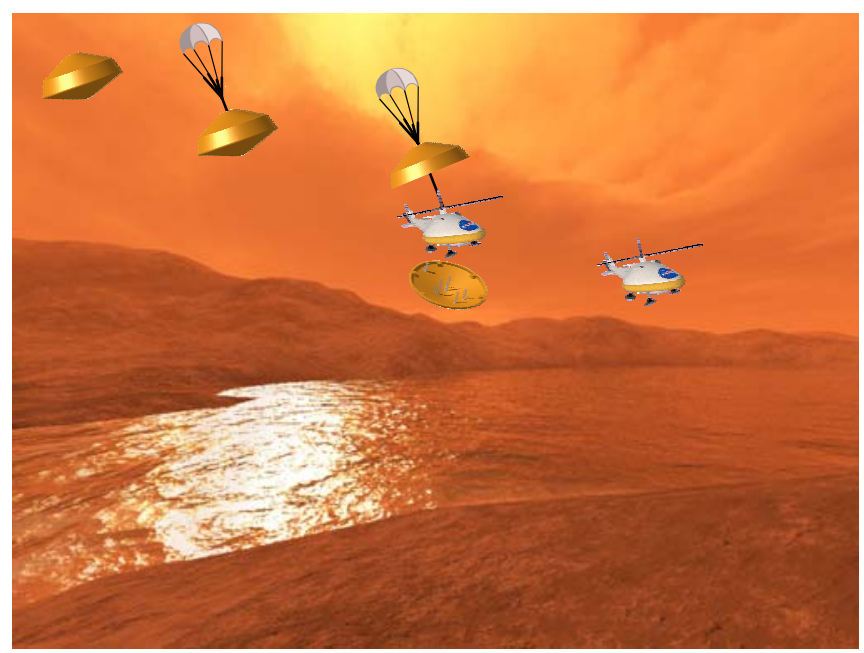

Figure 12 - EDT Schematic

During the two second interval when the helicopter is not attached to the parachute and the turbo expander is not attached to the shaft, autogyration will keep the helicopter in a stable orientation. Autogyration is the occurrence of the helicopter rotor spinning without power due to external forces. In this case, the blades can be oriented at a particular angle of attack so that as the helicopter is descending, the air pushing up on the blades causes them to rotate. This rotation will keep the helicopter stable in its descent through the atmosphere. Many current helicopters have the ability to land unpowered using autogyration. With the current entry, descent, and transition configuration, the helicopter can fly around Titan until it finds an appropriate landing spot.

\section{Operations}

From the moment the helicopter leaves the aeroshell, the turbo expander cycle will be operating at full capacity. Even though constantly running the moving parts will increase the rate of mechanical wear, having the turbo expander operate continuously will prevent mishaps from occurring from repeated starts. Also, as long the turbo expander is operating, the heat from the MMRTGs is carried away into the atmosphere, so there does not have to be a massive heat removal system. When the helicopter is on the surface, the alternator simply does not supply power to the electric motor, but still supplies power to the other subsystems including the scientific payload. When the helicopter wants to go explore Titan, a solid state relay will complete the circuit and supply power from the alternator to the electric motor which will turn the helicopter rotor. While the rotor is spinning, there is still enough power for all the other subsystems to operate simultaneously, and the helicopter can always take science measurements.

The helicopter will be able to communicate with the orbiter for about 38 minutes during every flyby. During these orbital flybys, the helicopter can be transmitting data while in the atmosphere or on the surface. However, since the flybys will occur about once every 8 or so days, the helicopter will have to travel autonomously without the ability to communicate with the orbiter. The inherent risk in traveling without communications is that if something goes wrong and the helicopter crashes, there may be no way of knowing what happened. However, if the helicopter only traveled during the communication window with the orbiter, it would only be able to explore about $10 \mathrm{~km}$ in that time while ensuring that it would be able to land in a safe spot. On the other hand, if the helicopter was allowed to operate without the restriction of communicating with the orbiter, it could travel a much greater distance (over $3000 \mathrm{~km}$ ) and find the most scientifically interesting parts of Titan. In addition, there would be ample time to be certain that the landing location was safe. In this scenario, the helicopter could travel around the entire moon several times in its mission lifetime.

\section{Planetary Protection}

Because the helicopter is a lander system that is not directly searching for life, it requires Category IV-A planetary protection considerations. As a result, exposed external and internal surfaces have a maximum allowable spore count of $3 \times 10^{5}$ and a maximum average spore density requirement of 300 spores $/ \mathrm{m}^{2}$.

To reduce the number of organisms on the spacecraft as much as possible, heat resistant components will be subjected to dry heat microbial reduction, which will raise them to a temperature of $125^{\circ} \mathrm{C}$ for a period of 50 hours. The number of accountable surfaces will be minimized using HEPA filters which can remove $99.97 \%$ of all particles greater than $3 \times 10^{-7} \mathrm{~m}$ in size. Any non-sealed components which are not heat tolerant will be prepared using alcohol wipes and hydrogen peroxide sterilization, which involves the evacuation of the sterilization chamber to form a vacuum and the injection of hydrogen peroxide into the chamber to establish a specified vapor concentration. Furthermore, the spacecraft components will be assembled in a Class 100,000 clean room to reduce the chance of contamination [8].

The helicopter's planetary protection procedures will be well documented. Authorities will be provided with a prelaunch planetary protection report which will document the 
degree to which all requirements have been met and will include the values of the microbial burden at launch and an inventory of all organics onboard the spacecraft, including the graphite bearings in the propulsion system. Next, a post-launch planetary protection report will be submitted which will update the pre-launch planetary protection report. Finally, after the mission has been completed, an end-of-mission report which will provide a complete report of compliance and the final disposition of all launched hardware will be submitted [8].

\section{BENEFIT OF CUSTOM RTG}

In addition, while the three MMRTGs fit inside the helicopter, more than one is not actually necessary since the only important aspect of the MMRTGs from the turbo expander perspective is the general purpose heat source (GPHS) cores. If a custom Nuclear Thermal source could be created with the same case dimensions as the MMRTG but additional GPHS units, then the mission could be achieved without sacrificing internal volume. Given that the GPHS cubes measure $10 \mathrm{~cm} \times 10 \mathrm{~cm} \times 5 \mathrm{~cm}$, it is possible to fit 4 stacks of 8 GPHS units in the standard MMRTG casing, as is shown in Figure 13.

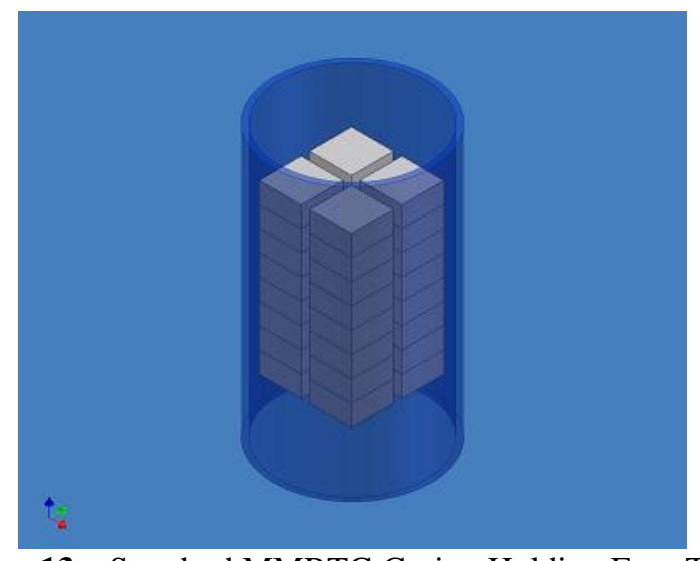

Figure 13 - Standard MMRTG Casing Holding Four Times the GPHS Units

The key advantage of the custom system is that it is quite lightweight and compact, taking up less volume than a similarly capable storage bank of batteries would. Since both ideas use an MMRTG, the mass and volume of the MMRTG is common to both systems. The remaining difference lies in the volume needed for a small gas turbine versus the volume for a large battery pack array. In essence, the volume saved from using the turbo expander would lower the required structural mass and hence reduce the power required for flight.

\section{Conclusions}

In this study, a long range, long duration helicopter was designed for the exploration of the surface and atmosphere of Saturn's moon Titan. After an extensive down-selection process, a double blade helicopter concept was chosen for the mission based on its demonstrated reliability on Earth and its low blade drag in Titan's dense atmosphere. Due to the high power requirements for helicopter flight and the long duration of the baseline mission, a unique turbo expander power generation concept was developed in which Titan's cold atmosphere is heated with RTG waste heat and expanded to perform useful work, generating the approximately $1.9 \mathrm{~kW}$ required to operate the helicopter. Other major subsystems were designed and sized as well.

An Entry, Descent, and Transition to flight sequence was developed in which the helicopter emerges from the aeroshell and immediately begins flight as the system enters the Titan atmosphere. A landing-first sequence in which the system would land on the surface before the helicopter commenced flight was considered but ruled out due to mass limitations. The helicopter also has a floatation device designed to keep the helicopter afloat in the event that it lands in liquid methane at any point during its mission.

The proposed helicopter concept provides VTOL capabilities on Titan and allows for a long duration mission. It is versatile in that it would study the surface, atmosphere, and possible methane oceans and its use of an in-situ resource for power generation means that the length of the mission is only limited by eventual mechanical failure. The concept does however require a high-risk transition to flight as the helicopter enters and descends through the Titan atmosphere. Also, the use of a helicopter introduces risk with so little known about the surface terrain on Titan due to possible hazards obstructing the helicopter's landing. Future work should include further analysis of the turbo expander power generation system and the possibility of autonomous hazard avoidance.

\section{APPENDIX}

Appendix A - Vehicle Salient Parameters

\begin{tabular}{|l|c|c|}
\hline & $\begin{array}{c}\text { Unit } \\
\text { s }\end{array}$ & Value \\
\hline Dimensions & & \\
\hline Length (includes tail) & $\mathrm{m}$ & 3.37 \\
\hline $\begin{array}{l}\text { Width (with flotation device } \\
\text { deflated) }\end{array}$ & $\mathrm{m}$ & 0.78 \\
\hline $\begin{array}{l}\text { Width (with flotation device } \\
\text { inflated) }\end{array}$ & $\mathrm{m}$ & 0.99 \\
\hline Height & $\mathrm{m}$ & 1.0 \\
\hline Fuselage Length & $\mathrm{m}$ & 2.56 \\
\hline Fuselage Height & $\mathrm{m}$ & 0.77 \\
\hline Number of Blades & - & 2 \\
\hline
\end{tabular}




\begin{tabular}{|l|c|c|}
\hline Main Rotor Diameter & $\mathrm{m}$ & 3.0 \\
\hline Main Blade Chord & $\mathrm{m}$ & 0.1 \\
\hline Tail Length & $\mathrm{m}$ & 0.75 \\
\hline Number of Tail Blades & - & 2 \\
\hline Tail Rotor Radius & $\mathrm{m}$ & 0.3 \\
\hline & & \\
\hline Performance & & \\
\hline Altitude Ceiling & $\mathrm{km}$ & 10 \\
\hline Range & - & $100.0 \mathrm{~km} *$ \\
\hline Maximum Cruise Velocity & $\mathrm{m} / \mathrm{s}$ & 4.0 \\
\hline Optimal Cruise Velocity & $\mathrm{m} / \mathrm{s}$ & 2.8 \\
\hline Maximum Rate of Climb & $\mathrm{m} / \mathrm{s}$ & 4.0 \\
\hline Power System & - & Turbo \\
& & Expander \\
\hline & & \\
\hline Weights & & 318.8 \\
\hline Gross Mass & $\mathrm{kg}$ & 36.0 \\
\hline Payload Mass & $\mathrm{kg}$ & \\
\hline
\end{tabular}

* Limited by navigational uncertainty, IMUs need recalibration about every 7 hours or $100.0 \mathrm{~km}$. 


\begin{tabular}{|c|c|c|c|c|}
\hline & \multicolumn{4}{|c|}{ Mass } \\
\hline Subsystem & $\begin{array}{l}\text { Total CBE } \\
\text { Mass (kg) }\end{array}$ & Contingency & $\begin{array}{l}\text { Max. Expected } \\
\text { Mass (kg) }\end{array}$ & $\begin{array}{c}\text { Max. Expected Mass } \\
\text { with } 30 \% \text { Margin (kg) }\end{array}$ \\
\hline Propulsion & 7.69 & & 9.99 & 12.99 \\
\hline Main Rotor & 4.36 & - & 5.67 & 7.37 \\
\hline Blade & 3.96 & $30 \%$ & 5.15 & 6.70 \\
\hline Axel & 0.40 & $30 \%$ & 0.52 & 0.67 \\
\hline Motor & 3.33 & $30 \%$ & 4.33 & 5.63 \\
\hline Power (Gas Expander) & 57.38 & & 74.59 & 96.97 \\
\hline 2nd Generation MMRTG & 51.00 & $30 \%$ & 66.30 & 86.19 \\
\hline Battery (for startup) & 0.28 & $30 \%$ & 0.37 & 0.48 \\
\hline Turbomachinery & 3.94 & - & 5.12 & 6.66 \\
\hline Turbine & 0.90 & $30 \%$ & 1.16 & 1.51 \\
\hline Compressor & 0.90 & $30 \%$ & 1.16 & 1.51 \\
\hline Piping & 2.15 & $30 \%$ & 2.80 & 3.63 \\
\hline Electric Motor & 1.08 & $30 \%$ & 1.40 & 1.82 \\
\hline Alternator & 1.08 & $30 \%$ & 1.40 & 1.82 \\
\hline Structure & 44.06 & & 53.80 & 69.94 \\
\hline Structural Mass & 36.42 & $30 \%$ & 47.34 & 61.54 \\
\hline Landing Gear & 4.61 & $40 \%$ & 6.46 & 8.39 \\
\hline Inflatable Tube & 2.60 & & 3.38 & 4.39 \\
\hline Flotation Tube (empty) & 1.31 & $30 \%$ & 1.71 & 2.22 \\
\hline Helium Gas Cartridges for Tube & 1.29 & $30 \%$ & 1.67 & 2.17 \\
\hline Communication & 23.21 & & 28.68 & 37.28 \\
\hline X-Band Omni - LGA & 0.114 & $30 \%$ & 0.15 & 0.19 \\
\hline SDST X-up/X-down & 2.7 & $30 \%$ & 3.51 & 4.56 \\
\hline X-Band TWTA & 2.1 & $10 \%$ & 2.31 & 3.00 \\
\hline UHF Transceiver & 4.9 & $20 \%$ & 5.88 & 7.64 \\
\hline UHF Transceiver & 4.9 & $20 \%$ & 5.88 & 7.64 \\
\hline UHF Omni & 1.5 & $30 \%$ & 1.95 & 2.54 \\
\hline UHF Diplexer & 1 & $20 \%$ & 1.20 & 1.56 \\
\hline $\begin{array}{ll}\text { Additional } & \text { Hardware } \\
\text { (switches, cables, etc.) } & \end{array}$ & 6 & $30 \%$ & 7.80 & 10.14 \\
\hline ADCS & 20.00 & & 23.97 & 31.15 \\
\hline Sun Sensors & 0.9 & $5 \%$ & 0.95 & 1.23 \\
\hline IMU & 4.5 & $5 \%$ & 4.73 & 6.14 \\
\hline IMU-Spare & 4.5 & $5 \%$ & 4.73 & 6.14 \\
\hline Radar Altimeter & 4.4 & $40 \%$ & 6.16 & 8.01 \\
\hline Antennas for Radar Altimeter & 0.32 & $30 \%$ & 0.42 & 0.54 \\
\hline Absorber for Radar Altimeter & 0.38 & $30 \%$ & 0.49 & 0.64 \\
\hline $\begin{array}{l}\text { Air Data System with pressure and } \\
\text { temperature }\end{array}$ & 5 & $30 \%$ & 6.50 & 8.45 \\
\hline
\end{tabular}




\begin{tabular}{|c|c|c|c|c|}
\hline \multirow[b]{2}{*}{ Subsystem } & \multicolumn{4}{|c|}{ Mass } \\
\hline & $\begin{array}{l}\text { Total CBE } \\
\text { Mass (kg) }\end{array}$ & Contingency & $\begin{array}{l}\text { Max. Expected } \\
\text { Mass (kg) }\end{array}$ & $\begin{array}{c}\text { Max. Expected Mass } \\
\text { with } 30 \% \text { Margin }(\mathrm{kg})\end{array}$ \\
\hline$C \& D H$ & 10.2 & & 12.40 & 16.12 \\
\hline $\begin{array}{l}\text { Flight Processor; >200 MIPS, } \\
\text { AD750, cPCI }\end{array}$ & 0.6 & $20 \%$ & 0.72 & 0.94 \\
\hline Digital I/O - CAPI Board & 0.6 & $20 \%$ & 0.72 & 0.94 \\
\hline $\begin{array}{l}\text { State of Health and Attitude Control } \\
\text { - SMACI }\end{array}$ & 0.6 & $20 \%$ & 0.72 & 0.94 \\
\hline Power Distribution - PDB & 1.2 & $20 \%$ & 1.44 & 1.87 \\
\hline Power Control - PCATI & 0.6 & $20 \%$ & 0.72 & 0.94 \\
\hline Mother Board & 0.8 & $20 \%$ & 0.96 & 1.25 \\
\hline $\begin{array}{l}\text { Power Converters (For Integrated } \\
\text { Avionics Unit) }\end{array}$ & 0.8 & $20 \%$ & 0.96 & 1.25 \\
\hline Chassis & 3.4 & $20 \%$ & 4.08 & 5.30 \\
\hline Solid State Data Recorder & 1.6 & $30 \%$ & 2.08 & 2.70 \\
\hline Thermal & 8.27 & & 10.75 & 13.98 \\
\hline $\begin{array}{l}4 \% \text { of s/c dry mass } \\
5 \% \text { of total subsystem power } \\
\text { Includes Multi-layer insulation (MLI), } \\
\text { (RHUs) }\end{array}$ & $\begin{array}{r}8.27 \\
\text { oop Heat Pipe }\end{array}$ & $\begin{array}{r}30 \% \\
\text { (LHP), Tempe }\end{array}$ & 10.75 & 13.98 \\
\hline Payload & 24.60 & & 27.66 & 35.96 \\
\hline $\begin{array}{l}\text { Panchromatic Visible Light Imager } \\
\text { (2) }\end{array}$ & 2.6 & $10 \%$ & 2.86 & 3.72 \\
\hline Mass Spectrometer & 10 & $10 \%$ & 11 & 14.30 \\
\hline Haze and Cloud Particle Detector & 3 & $30 \%$ & 3.9 & 5.07 \\
\hline Surface Composition Spectrometer & 5 & $10 \%$ & 5.5 & 7.15 \\
\hline Sun Seeking Spectrometer & 4 & $10 \%$ & 4.4 & 5.72 \\
\hline Total: Helicopter & 198.01 & & 245.22 & 318.79 \\
\hline Aeroshell Attachments & 23.08 & $30 \%$ & 30.00 & 39.00 \\
\hline $\begin{array}{lll}\text { Total } & \text { Mass } & \text { Inside } \\
\text { Aeroshell } & & \\
\end{array}$ & 221.09 & & 275.22 & 357.79 \\
\hline
\end{tabular}




\section{REFERENCES}

[1] Joel S. Levine, et al., "Titan Explorer: The Next Step in the Exploration of a Mysterious World,” NASA Vision Mission Study, 2005.

[2] R. V. Yelle, D. F. Strobell, E. Lellouch and D Gautier, "Engineering Models for Titan's Atmosphere," ESA SP-1177, 243-256, August 1997.

[3] Anthony Colozza, "Planetary Exploration Using Biomimetics,” NASA Institute for Advanced Concepts, November 2000.

[4] Jarret M. Lafleur, "Derivation and Application of a Methodology to Estimate Planetary Aerial Vehicle Power Requirements,” AIAA Region II Student Conference, Gainesville, April 4-5, 2005.

[6] Luke S. Colby, Robert D. Braun, Ravi Prakash, "Nuclear Gas Turbine Propulsion System for a Long Endurance Titan Aerial Vehicle," $41^{\text {st }}$ AIAA/ASME/SAE/ASEE Joint Propulsion Conference and Exhibit, July 10-13, 2005.

[7] Thompson, R., Francis, S., Olsen, R., Parsons, M., Coffman, R., Braun, R., "Cadmus: A Europa Scout Mission Proposal,” IEEE Aerospace Conference, March 5-12, 2005. 